\title{
Maturation of the Glucose Transport Process by the Fetal Kidney
}

\author{
JEAN E. ROBILLARD, ${ }^{(29)}$ CHRISTINE SESSIONS, ROLAND L. KENNEDY, \\ AND FRED G. SMITH, JR. \\ Department of Pediatrics, and the Department of Anesthesiology, University of Iowa, Iowa City, Iowa, USA
}

\begin{abstract}
Summary
In order to study the maturation of the glucose reabsorptive process by the fetal kidney, nine chronic fetal lamb preparations (0.66-3.72 kg) were studied and values compared to data obtained from four nonpregnant ewes. Blood and urine control values showed there was a close relationship between fetal glomerular filtration rate (GFR $\mathrm{ml} / \mathrm{min}$ ) and fetal body weight $(r=0.78, P<0.02)$. The fractional excretion of sodium, during control periods, varied from $3.86-14.76 \%$, but no relation with fetal weight or fetal GFR $\mathrm{ml} / \mathrm{min}$ was found. The mean value for blood glucose observed at threshold was higher in the fetus $(200 \pm 13.3 \mathrm{mg} / 100 \mathrm{ml})$ than in adult ewes $(177 \pm 2.8 \mathrm{mg} / 100$ $\mathrm{ml})$. Fetal glucose threshold was correlated to fetal body weight $(r=0.71, P<0.05)$ and fetal GFR $\mathrm{ml} / \mathrm{min}(r=0.74, P<$ 0.025). The maximum amount of glucose reabsorbed expressed per unit of GFR ( $\mathrm{Tm}_{\mathrm{G}} /$ GFR) was reached only in one fetus and was 4.73. In all other fetuses, $T m_{G}$ was not reached since metabolic acidosis developed during the course of glucose infusion. However, in those fetuses, the highest amount of glucose reabsorbed expressed per unit of GFR ( $\left.T_{G} / G F R\right)$, before glucose infusion was stopped, varied from 2.32 to 3.85 with a mean of $2.83 \pm 0.26$. In the adult ewes $T \mathrm{~m}_{\mathrm{G}} / \mathrm{GFR}$ varied from 1.94 to 2.47 , and the mean value $(2.21 \pm 0.12)$ was significantly lower $(P<0.05)$ than the mean $\mathbf{T m}_{\mathrm{G}} / \mathbf{G F R}$ and $\mathbf{T}_{\mathrm{G}} /$ GFR values found in fetuses. These data indicate that the plasma threshold values for glucose reabsorption by the fetal kidney increased with fetal GFR, suggesting that there is a parallel development in fetal tubular and glomerular function. Moreover, the fact that fetal $\mathbf{T m}_{\mathrm{G}} /$ GFR and $\mathbf{T}_{\mathrm{G}} /$ GFR were higher than adult $\mathbf{T} \mathrm{m}_{\mathrm{G}} /$ GFR suggests that there is no functional correlate to the documented anatomic glomerular preponderance during fetal life.
\end{abstract}

\section{Speculation}

The higher capacity of the fetal renal tubule to reabsorb glucose may be explained both by a prolonged transit time of the glomerular filtrate through the proximal tubule and an increase in proximal tubular volume. However, the capacity of the distal tubule to reabsorb glucose, the degree of permeability of the fetal renal tubule, and the importance of inner versus outer nephrons need to be evaluated in order to determine their effect on the renal capacity of the fetal kidney to reabsorb glucose.

Early investigation demonstrated that the capacity of the newborn tubule to reabsorb glucose was limited when compared to the adult $(23,24)$. Absolute values for maximal tubular glucose reabsorption $\left(\mathrm{Tm}_{\mathrm{G}}\right)$, corrected for body weight or surface area, were found to be lower in premature and term infants than in adults $(23,24)$. The same investigators also demonstrated the $\mathrm{Tm}_{\mathrm{G}} /$ GFR ratio to be lower during the newborn period than later in life-suggesting that the tubular function was more immature than the glomerular function at birth (24). However, Brodehl (6), Baker (4), and Arant (2) were recently able to demonstrate that the maximal glucose reabsorption per milliliter of glomerular filtrate $\left(\mathrm{Tm}_{\mathrm{G}} / \mathrm{GFR}\right)$ was equal to or slightly higher than adult levels during the first weeks of life, thereby suggesting that glomerular tubular balance was maintained.

It has been demonstrated during fetal life in rats (8), pigs (16), and lambs (1) that the fetal renal tubule reabsorbs glucose. Alexander and Nixon (1) suggested that the fetal lamb kidney has the capacity to reabsorb most of the filtered glucose before the midpoint of gestation, confirming a previous study on the mesonephros of fetal pigs (16). They also demonstrated that phlorizin blocked glucose reabsorption (1).

These fetal studies $(1,8,16)$, however, were done in acute fetal preparations in which the renal function might have been altered considerably by stress and hypoxia $(11,20)$. The present work was designed to study, in chronic fetal sheep preparations, the maturation of the glucose reabsorptive process by the fetal kidney during the last trimester of gestation.

\section{MATERIALS AND METHODS}

Nine chronic fetal lamb preparations (mixed breed Dorset and Suffolk) and four nonpregnant ewes were used to investigate the renal process of glucose reabsorption. The intrauterine fetal weight at the time of the experiment was estimated according to the equation formulated by Gresham (11): log fetal weight $(\mathrm{g})=\log$ birth weight $(\mathrm{g})-0.0153 \times \Delta \mathrm{t}(\Delta \mathrm{t}$ represents the time difference between day of delivery and day of estimate of fetal weight).

\section{SURGICAL PROCEDURES}

In all fetuses, the chronic indwelling catheter preparation was utilized and has been described previously (19). Each pregnant ewe was fasted for $48 \mathrm{hr}$ before fetal surgery and a mixture of halothane, oxygen $(40 \%)$, and nitrous oxide $(60 \%)$ was given by an endotracheal tube for general anesthesia. After a midline incision, the tip of the uterine horn was exposed, and the hind leg of the fetus delivered. Polyethylene catheters were passed into the femoral vein and artery for a distance of approximately $5 \mathrm{~cm}$ and secured with silk ligatures. Through the same incision, the umbilical cord was then located, the urachus identified, and a French no. $31 / 2$ infant feeding tube inserted and advanced approximately $4-6 \mathrm{~cm}$ into the fetal bladder. All three catheters were secured with silk ligatures and a drop of methyl-2-cyanoacrylate (Eastman 910 adhesive, Eastman Chemical Products, Inc., Kingsport, TN) was applied for tissue adhesion. Thereafter, the hind limb was replaced and the fetal membranes, uterine wall, and abdominal cavity were closed in separate layers with 0 catgut sutures. All catheters were then exteriorized through a subcutaneous tunnel and placed in a cloth pouch on 
the animal's flank, after which the abdominal skin was closed. Another polyethylene catheter was inserted into the lower abdominal aorta of the ewe through a tributary of the superficial femoral artery.

Using local anesthesia (2\% lidocaine hydrochloride solution, Xylocaine, Astra Pharmaceuticals, Inc., Worchester, MA) chronic catheters were placed in superficial femoral veins and arteries of four control nonpregnant ewes. On the day of the experiment a Foley catheter was inserted into the ewe's bladder and maintained in place.

After surgery, the ewes were kept in a restricted area and fed a standard diet. The animals were usually standing and eating within $1 \mathrm{hr}$ postsurgery. Ampicillin ( $1 \mathrm{~g}$ every $8 \mathrm{hr}$ ) and streptomycin (500 mg daily) were given im for the first 2 days after surgery. A recovery period of at least 6 days was required before any experiments were carried out. During the recovery period the urachal catheter was closed and urine was excreted in the amniotic cavity via the urethra.

\section{PHYSIOLOGIC STUDIES}

In each fetal preparation the glomerular filtration rate was determined by a constant infusion $(0.04 \mathrm{ml} / \mathrm{min})$ of sodium [ ${ }^{125}$ I] iothalamate (Glofil, Abbott Laboratories, North Chicago, IL) (approximately $0.1 \mu \mathrm{C} / \mathrm{min} / \mathrm{kg}$ ) into the fetal femoral vein. An equilibration period of at least $60 \mathrm{~min}$ was allowed before the first clearance period. Three control collections at 15-min intervals were then obtained to measure GFR, electrolyte ( $\mathrm{Na}$, $\mathrm{K}, \mathrm{Cl}$ ) excretion, and glucose reabsorption as described previously (19). Thereafter, in order to raise plasma glucose concentrations in the fetus, we found that it was necessary to administer a priming dose of $200 \mathrm{ml}$ of a $30 \%$ glucose solution containing $20 \mathrm{mEq} / \mathrm{liter}$ of $\mathrm{KCl}$ to the mother followed by a constant infusion of the same solution at a rate of $2.2 \mathrm{ml} / \mathrm{min}$ for the duration of the experiment. Simultaneously, the same $30 \%$ glucose solution was administered iv to the fetus at varying rates (from $0.15-0.35 \mathrm{cc} / \mathrm{min}$ ) to produce the desired plasma glucose concentrations. Potassium chloride was added to the solution to prevent hypokalemia as noticed in preliminary experiments when glucose alone was infused. For each infusion rate, at least three collection periods were established at 15-min intervals in order to measure GFR, excretion of electrolytes, and glucose reabsorption. Whenever the rate of glucose infusion was changed in the fetus, a 20-min equilibration period was allowed.

Adult control values for renal glucose reabsorption were also determined in four nonpregnant ewes. After the establishment of three control collection periods at 15 -min intervals for measurement of GFR, excretion of electrolytes, and glucose reabsorption, the blood glucose concentrations were raised in a steplike fashion using a $30 \%$ glucose solution containing 20 $\mathrm{mEq} /$ liter of $\mathrm{KCl}$ administered at varying rates (from $0.5 \mathrm{cc} / \mathrm{min}$ up to $2.5 \mathrm{cc} / \mathrm{min}$ ). A 20 -min equilibration period was then allowed whenever the rate of glucose infusion was changed.

In both the fetuses and nonpregnant adult ewes, arterial blood samples were collected at the midpoint of each collection period for $\mathrm{pH}$, blood gases, plasma electrolytes, and glucose determination.

\section{ANALYTIC METHODS}

Sodium [ $\left.{ }^{125} \mathrm{I}\right]$ iothalamate was counted in blood and urine samples with a gamma spectrometer (Beckman Gamma 300 system, Beckman Instruments, Inc., Creve Coeur, MO). Sodium concentrations were measured by flame photometry (5) and chloride concentration by potentiometric titration (7). Blood for measurement of $\mathrm{pH}, \mathrm{PCO}_{2}$, and $\mathrm{PO}_{2}$ was collected anaerobically in heparinized glass syringes and immediately processed using appropriate $\mathrm{pH}, \mathrm{PCO}_{2}$ and $\mathrm{PO}_{2}$ electrodes (Radiometer PHM 72 MK2 acid-base analyzer, Radiometer Co., Copenhagen, Denmark) at $39^{\circ}$. Blood glucose was measured by a glucose oxidase method (21).
DATA ANALYSIS

The renal threshold for glucose was taken at the plasma level at which glucose was first detected in the urine in increasing amounts. The maximum amount of glucose reabsorbed $\left(\mathrm{Tm}_{\mathrm{G}}\right)$ was calculated by averaging all values for $\mathrm{T}$ glucose after glucose reabsorption became relatively stable and when filtered glucose loads exceeded the amount of glucose reabsorbed by a factor of 1.5. Data was evaluated using the $t$-test for paired data to compare control to experimental values in the same group of animals, and for unpaired data for comparisons between groups. The regression curves were derived by the method of least squares. The term "significant" is used throughout the paper to describe changes with a $p$ value of less than 0.05 in a two-sided significance limit. The results are presented as mean \pm SEM.

\section{RESULTS}

Blood and urine control values from nine fetal lambs and four adult nonpregnant ewes before the infusion of glucose, are presented in Table 1 . There was a close relationship between fetal GFR $\mathrm{ml} / \mathrm{min}$ and fetal body weight $(r=0.78, P<0.02$; see Fig. 1). There was no increase, however, in GFR $\mathrm{ml} / \mathrm{min} / \mathrm{kg}$ $(1.023 \pm 0.11 \mathrm{ml} / \mathrm{min} / \mathrm{kg})$ in relation to fetal body weight. The fractional excretion of sodium varied from 3.86 to $14.76 \%$ but no relation to fetal weight or fetal GFR was found.

\section{GLUCOSE THRESHOLD DETERMINATION}

Values for blood glucose observed at threshold in fetal lambs and nonpregnant ewes are summarized in Table 2. Mean fetal values for blood glucose at threshold $(200 \pm 13.3 \mathrm{mg} / 100 \mathrm{ml})$ were higher than the mean adult values $(177 \pm 2.8 \mathrm{mg} / 100 \mathrm{ml})$.

Analysis of fetal and adult glucose threshold as a function of body weight is summarized in Figure 2 . There was a significant positive correlation $(P<0.05, r=0.71)$ between fetal glucose threshold and fetal body weight while there was no correlation in the adult. Moreover, a significant correlation was found between fetal glucose threshold and fetal control GFR $\mathrm{ml} / \mathrm{min}$ $(P<0.025, r=0.74)$.

Mean values for fetal $\mathrm{PCO}_{2}$ and $\mathrm{PO}_{2}$ at threshold (45.8 \pm 1.36 and $24.15 \pm 1.28 \mathrm{~mm} \mathrm{Hg}$ ) were not significantly different than mean control values $(44.1 \pm 1$ and $25.5 \pm 9.95 \mathrm{~mm} \mathrm{Hg})$. However, the mean fetal $\mathrm{pH}$ at threshold $(7.29 \pm 0.02)$ was significantly lower $(P<0.01)$ than the mean fetal control $\mathrm{pH}$ $(7.38 \pm 0.01)$. Values for fetal GFR at threshold $(2.64 \pm 0.46)$ were slightly but significantly higher $(P<0.05)$ than the mean control GFR values $(2.06 \pm 0.33)$. Fetal fractional excretion of sodium was significantly lower $(P<0.05)$ at threshold $(6.84 \pm$ $1.09 \%)$ than before glucose infusion $(8.34 \pm 1.13 \%)$. In the adult nonpregnant ewes, there was no significant change for $\mathrm{pH}$, blood gases, GFR, and fractional excretion of sodium when control values were compared to values at threshold.

\section{MAXIMAL TUBULAR REABSORPTION OF GLUCOSE}

$\mathrm{Tm}_{\mathrm{G}}$ was reached only in fetus 1 and was 4.73 when expressed per unit of GFR $\left(\mathrm{Tm}_{\mathrm{G}} / \mathrm{GFR}\right)$. In that particular fetus, $\mathrm{pH}$ was $7.31, \mathrm{PCO}_{2} 48.9 \mathrm{~mm} \mathrm{Hg}, \mathrm{PO}_{2} 24.4 \mathrm{~mm} \mathrm{Hg}$, GFR $1.58 \mathrm{ml} / \mathrm{min}$ and fractional excretion of sodium $14.45 \%$. In all other fetuses, we were unable to reach the $\mathrm{Tm}_{\mathrm{G}}$ since metabolic acidosis developed during the course of glucose infusion. However, before glucose infusion was stopped, the highest amount of glucose reabsorbed, expressed per unit of GFR ( $\left.\mathrm{T}_{\mathrm{G}} / \mathrm{GFR}\right)$, varied from 2.32 to 3.85 with a mean of $2.83 \pm 0.26$.

In the adult nonpregnant ewes the maximum amount of glucose reabsorbed expressed per unit of GFR $\left(\mathrm{Tm}_{\mathrm{G}} / \mathrm{GFR}\right)$ varied from 1.94 to 2.47 with a mean of $2.21 \pm 0.12$. Also, there was no significant difference at $\mathrm{Tm}_{\mathrm{G}}$ for $\mathrm{pH}, \mathrm{PCO}_{2}, \mathrm{PO}_{2}$, GFR, and fractional excretion of sodium when compared to control values.

The $\mathrm{Tm}_{\mathrm{G}} / \mathrm{GFR}$ in fetus 1 and the mean value for $\mathrm{T}_{\mathrm{G}} / \mathrm{GFR}$ for 
Table 1. Blood and urine values

\begin{tabular}{|c|c|c|c|c|c|c|c|c|c|c|c|}
\hline & \multicolumn{8}{|c|}{ Blood } & \multicolumn{3}{|c|}{ Urine } \\
\hline & \multirow{2}{*}{\multicolumn{2}{|c|}{$\begin{array}{c}\text { Weight } \\
\mathrm{Kg}\end{array}$}} & \multirow[t]{2}{*}{$\mathrm{pH}$} & $\mathrm{PCO}_{2}$ & $\mathrm{PO}_{2}$ & Not & $\mathbf{K}^{+}$ & \multirow{2}{*}{$\begin{array}{l}\text { Glucose } \\
\mathrm{mg} / 100 \mathrm{ml}\end{array}$} & \multirow{2}{*}{$\begin{array}{l}\text { GFR } \\
\mathrm{ml} / \mathrm{min}\end{array}$} & FENa* & \multirow{2}{*}{$\begin{array}{c}\text { Glucose excreted } \\
\mathrm{mg} / \mathrm{min}\end{array}$} \\
\hline & & & & \multicolumn{2}{|c|}{$\mathrm{mmHg}$} & \multicolumn{2}{|c|}{ meq/I } & & & $\%$ & \\
\hline \multirow[t]{9}{*}{ Fetus } & 1 & 0.666 & 7.37 & 48.2 & 22.2 & 142 & 3.43 & $45.0 \pm 2.88$ & $0.904 \pm 0.24$ & $7.03 \pm 0.45$ & 0 \\
\hline & 2 & 3.720 & 7.40 & 42.0 & 30.2 & 146 & 4.60 & $13.0 \pm 0.62$ & $2.450 \pm 0.57$ & $6.50 \pm 0.87$ & 0 \\
\hline & 3 & 3.000 & 7.40 & 38.8 & 27.4 & 140 & 4.43 & $9.6 \pm 0.33$ & $2.340 \pm 0.08$ & $8.73 \pm 0.58$ & 0 \\
\hline & 4 & 2.470 & 7.38 & 45.6 & 27.7 & 150 & 3.86 & $10.0 \pm 0.10$ & $2.880 \pm 0.64$ & $14.76 \pm 1.05$ & 0 \\
\hline & 5 & 1.020 & 7.36 & 42.3 & 26.8 & 143 & 3.64 & $18.0 \pm 1.52$ & $0.662 \pm 0.14$ & $12.06 \pm 1.23$ & 0.01 \\
\hline & 6 & 1.780 & 7.39 & 45.1 & 24.4 & 143 & 3.36 & $22.3 \pm 1.45$ & $1.996 \pm 0.11$ & $9.90 \pm 0.61$ & 0 \\
\hline & 7 & 0.846 & 7.35 & 46.9 & 21.7 & 145 & 4.66 & $26.3 \pm 0.66$ & $1.180 \pm 0.06$ & $6.56 \pm 0.14$ & 0 \\
\hline & 8 & 2.750 & 7.40 & 42.1 & 26.3 & 151 & 3.86 & $16.0 \pm 0.57$ & $3.790 \pm 1.07$ & $3.86 \pm 0.14$ & 0.01 \\
\hline & 9 & 2.950 & 7.40 & 46.4 & 23.0 & 149 & 3.60 & $23.3 \pm 2.02$ & $2.390 \pm 0.28$ & $5.73 \pm 0.41$ & 0 \\
\hline \multirow[t]{4}{*}{ Adult } & 1 & 40.8 & 7.53 & 35.1 & 107 & 142 & 3.05 & $99.6 \pm 2.33$ & $71.00 \pm 2.44$ & $1.71 \pm 0.08$ & $0.28 \pm 0.04$ \\
\hline & 2 & 49.0 & 7.52 & 31.0 & 99 & 144 & 3.16 & $62.0 \pm 1.44$ & $118.60 \pm 1.34$ & $1.41 \pm 0.15$ & $0 \pm 0$ \\
\hline & 3 & 34.6 & 7.49 & 34.0 & 95 & 142 & 3.56 & $63.0 \pm 1.43$ & $75.71 \pm 2.30$ & $0.69 \pm 0.20$ & $0 \pm 0$ \\
\hline & 4 & 42.0 & 7.49 & 31.0 & 106 & 147 & 3.46 & $81.0 \pm 2.08$ & $107.21 \pm 0.98$ & $0.34 \pm 0.11$ & $0.05 \pm 0.01$ \\
\hline
\end{tabular}

1 GFR: glomerular filtration rate; $\mathrm{FE}_{\mathrm{Na}}+\%$ : percentage of filtered sodium excreted.

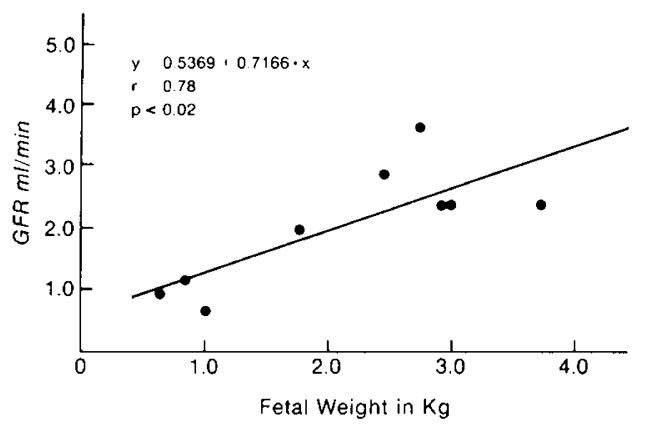

Fig. 1. Relationship between fetal body weight and GFR.

Table 2. Blood and urine values observed at threshold for glucose ${ }^{1}$

\begin{tabular}{|c|c|c|c|c|c|c|c|}
\hline & & \multicolumn{4}{|c|}{ Blood } & \multicolumn{2}{|c|}{ Urine } \\
\hline & & \multirow[t]{2}{*}{$\mathrm{pH}$} & $\mathrm{PCO}_{2}$ & $\mathrm{PO}_{2}$ & Glucose & GFR & FENa ${ }^{+}$ \\
\hline & & & \multicolumn{2}{|c|}{$\mathrm{mmHg}$} & $\mathrm{mg} / 100 \mathrm{ml}$ & $\mathrm{ml} / \mathrm{min}$ & $\%$ \\
\hline \multirow[t]{9}{*}{ Fetus } & 1 & 7.38 & 44.7 & 23.7 & 140 & 1.00 & 6.64 \\
\hline & 2 & 7.25 & 43.0 & 31.7 & 209 & 4.11 & 3.45 \\
\hline & 3 & 7.33 & 40.0 & 23.6 & 217 & 3.91 & 6.76 \\
\hline & 4 & 7.20 & 51.6 & - & 276 & 3.39 & 13.90 \\
\hline & 5 & 7.31 & 48.8 & 25.9 & 167 & 0.95 & 7.80 \\
\hline & 6 & 7.35 & 45.3 & 25.2 & 200 & 2.50 & 8.10 \\
\hline & 7 & 7.22 & 51.8 & 21.1 & 163 & 0.93 & 3.35 \\
\hline & 8 & 7.35 & 42.2 & 22.0 & 207 & 4.34 & 3.70 \\
\hline & 9 & 7.22 & 45.6 & 20.0 & 223 & 2.67 & 7.92 \\
\hline \multirow[t]{4}{*}{ Adult } & 1 & 7.54 & 32.7 & 105 & 178 & 76.6 & 1.89 \\
\hline & 2 & 7.52 & 31.1 & 102 & 177 & 132.6 & 2.56 \\
\hline & 3 & 7.50 & 34.3 & 105 & 185 & 93.0 & 1.22 \\
\hline & 4 & 7.47 & 31.3 & 112 & 171 & 90.9 & 1.00 \\
\hline
\end{tabular}

1 GFR: glomerular filtration rate: $\mathrm{FE}_{\mathrm{Na}}+\%$ : percentage of filtered sodium excreted.

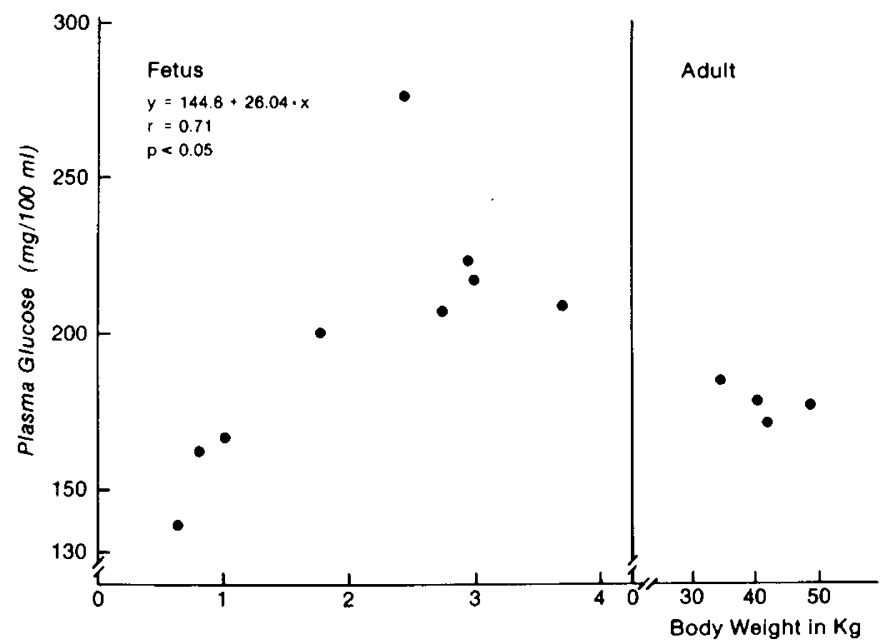

Fig. 2. Fetal and adult plasma glucose at threshold as a function of body weight.

all other fetuses were significantly higher than the mean adult $\mathrm{Tm}_{\mathrm{G}} / \mathrm{GFR}(P<0.05)$.

\section{DISCUSSION}

The use of the chronic fetal model permitted the investigators to study the capacity of the fetal kidney to reabsorb glucose at different times during gestation in well oxygenated fetuses during steady state. In view of a recent study which suggested unstable values for maternal and fetal plasma glucose during the first 4 postoperative days (22), a recovery period of at least 6 days was allowed. Moreover, it is well known that re-establishment of normal fetoplacental circulation and fetal renal function after surgery may require up to 5 postoperative days $(11,20)$.

The presence of a close relationship between fetal GFR $\mathrm{ml} /$ min and fetal body weight (Fig. 1), as well as the absence of an increase in GFR expressed in milliliters per min per $\mathrm{kg}$ related to fetal body weight, concurs with previous studies done by our group $(17,19)$ but differs from a recent acute study using fetal guinea pigs (15). 
The present study also demonstrates that the fetus can reabsorb glucose very early in gestation and confirms previous results $(1,8,16)$. It shows that the renal glucose threshold increased with fetal body weight and is higher than the mean adult glucose threshold (Fig. 2). A positive regression of glucose threshold with age was also found by Arant and coworkers (2) in puppies. However, contrary to the present study where the glucose threshold of fetuses over $2 \mathrm{~kg}$ body wt is higher than the adult threshold, all threshold values found in Arant's study (2) fell within the $95 \%$ confidence limits for the glucose threshold of adult dogs.

Although the threshold for glucose reabsorption is higher in the older fetuses than in adult sheep, this does not necessarily imply that the $\mathrm{Tm}_{\mathrm{G}}$ corrected for the GFR $\left(\mathrm{Tm}_{\mathrm{G}} / \mathrm{GFR}\right)$ is higher in the fetus. The presence of a minimal degree of splay in the fetus may explain this higher threshold without any modification in the $\mathrm{Tm}_{\mathrm{C}} / \mathrm{GFR}$. However, this is unlikely since the fetal kidney-as with the newborn kidney-probably presents a greater nephron heterogeneity than later in life. A recent study has shown that newborn puppies had a greater degree of splay than older animals (2). Hence, the present results suggest a higher fetal $T \mathrm{~m}_{\mathrm{G}} / \mathrm{GFR}$ ratio when compared to the adult $T \mathrm{~m}_{\mathrm{G}} /$ GFR ratio. When the $T m_{G}$ was reached in one fetus (fetus 1 ), it was found that $T m_{G} / G F R$ was 4.73 when the mean $T m_{G} / G F R$ value for the adult sheep was $2.21 \pm 0.12$. Moreover, the fetuses in which $\operatorname{Tm}_{G}$ was not reached, the highest amount of glucose reabsorbed $\left(\mathrm{T}_{\mathrm{G}}\right)$ when corrected for the GFR $\left(\mathrm{T}_{\mathrm{G}} / \mathrm{GFR}\right)$ was still significantly higher $(P<0.05)$ than the mean $\mathrm{Tm}_{\mathrm{G}} /$ GFR value for the adult sheep. Using an acute fetal sheep preparation, Alexander and Nixon (1) found in one fetus in which the $\mathrm{Tm}_{\mathrm{G}}$ was reached, that the fetal $\mathrm{Tm}_{\mathrm{G}} / \mathrm{GFR}$ was $50 \%$ higher than the mean $\mathrm{Tm}_{\mathrm{C}} /$ GFR value found in adult sheep.

Arant and Nixon (2) also demonstrated that the $T \mathrm{~m}_{\mathrm{G}}$ to GFR ratio was 1.5 times higher immediately after birth in newborn dogs than adult values. The present study and Arant's study (2) differ from previous studies in premature infants $(23,24)$ in which the $\mathrm{Tm}_{\mathrm{G}}$ to $\mathrm{C}_{\mathrm{in}}$ ratio during the first few days of life was lower than the adult ratio. Therefore, it is suggested that there is no functional correlate to the documented anatomic glomerular preponderance (9) during fetal life.

In order to explain the higher capacity of the fetal renal tubule to reabsorb glucose when compared to adult values, various factors must be considered. Keyes and Swanson (13) suggested that the number of glucose transport sites per nephron in contact with tubular fluid is a direct function of the tubular volume. They demonstrated that the $\mathrm{Tm}_{\mathrm{G}} / \mathrm{GFR}$ ratio increased after partial ureteral obstruction although both the GFR and $\operatorname{Tm}_{\mathrm{G}}$ decreased. There is evidence in the fetus which may favor an increase in proximal tubular volume; the fractional reabsorption of sodium is very low (19) and this low capacity to reabsorb sodium in the fetus is probably more important at the proximal than at the distal site as demonstrated in newborn dogs (14). Therefore, with less sodium being reabsorbed into the fetal proximal tubule, the nonreabsorbed fluid will increase tubular volume and the number of proximal microvilli exposed to tubular fluid. In addition to this mechanism, the transit time of glomerular filtrate through the proximal tubule may be longer in the fetus allowing more time to reabsorb glucose. Thus, the increase in tubular volume and/or a prolonged transit time for the glomerular filtrate may explain at least partially the higher $\mathrm{Tm}_{\mathrm{G}} / \mathrm{GFR}$ ratio in fetuses than in adults.

The high threshold for fetal glucose reabsorption and the high $\mathrm{Tm}_{\mathrm{G}} / \mathrm{GFR}$ ratio may also be secondary to an increased capacity of the fetal distal tubule and/or collecting duct to reabsorb glucose. Recently, Wen $(25,26)$ and Arruda (3) suggested that large amounts of glucose may be reabsorbed outside the proximal tubule in normoglycemic adult dogs. Wen (26) demonstrated that after extracellular volume expansion, fractional and absolute glucose excretions in the final urine were not increased despite a reduction in proximal tubule glucose reabsorption.
Similar data has also been reported in the rat (10). It was then suggested that a site distal to the proximal convoluted tubule had the capacity to completely reabsorb the excess distal delivery. A similar mechanism may also be present in the fetus and explain the fact that the fetus, while in a chronic state of extracellular volume expansion (18), may show a normal or even greater capacity to reabsorb glucose.

An increase in sodium reabsorption is also shown in the present study when threshold values are compared to control data. Imai (12) recently showed that increased glucose transport accelerated sodium reabsorption in isolated perfused proximal tubules. This may suggest that the decrease in sodium excretion seen in the present study may at least be partially influenced by an increased amount of glucose reabsorbed.

In summary, the present study demonstrates that the plasma threshold for renal glucose reabsorption increases with fetal body weight and becomes higher than the mean adult glucose threshold at the end of gestation. Moreover, the present results are in favor of a higher $\mathrm{Tm}_{\mathrm{c}} /$ GFR ratio in the fetuses than in the adults, suggesting the absence of a functional correlate to the documented anatomic glomerular preponderance during fetal life.

\section{REFERENCES AND NOTES}

1. Alexander, D. P., and Nixon, D. A.: Reabsorption of glucose, fructose and mesoinositol by the foetal and postnatal sheep kidney. J. Physiol. (Lond.), 167: 480 (1963)

2. Arant, B. S., Edelmann, C. M., Jr., and Nash, M. A.: The renal reabsorption of glucose in the developing canine kidney: A study of glomerulotubular balance. Pediat. Res. 8: 638 (1974)

3. Arruda, J. A. L., Westerfelder, C., Lockwood, R., and Kurtzman, N. A.: Glucose and bicarbonate reabsorption in edematous dogs. Amer. J. Physiol. 231: 749 (1976).

4. Baker, J. T., and Kleinman, L. I.: Relationship between glucose and sodium excretion in the newborn dog. J. Physiol. (Lond.), 243: 45 (1974)

5. Berry, S. W., Chappell, D. G., and Barnes, R. B.: Improved method of flame photometry. Ind. Eng. Chem. Anal. Ed., 18: 19 (1946).

6. Brodehl, J., Franken, A., and Gellissen, K.: Maximal tubular reabsorption of glucose in infants and children. Acta Paediat. Scand., 61: 413 (1972)

7. Cotlove, E., Trantham, H. V., and Bowman, R. L.: An instrument and method for automatic, rapid, accurate and sensitive titration of chloride in biologic samples. J. Lab. Clin. Med., 51: 461 (1958)

8. Daly, H., Wells, L. J., and Evans, G.: Experimental evidence of the secretion of urine by the fetal kidney. Proc. Soc. Exp. Biol. Med., 64: 78 (1974).

Fetterman, G. H., Shuplock, N. A., Philipp, B. S., and Gregg, H. S.: The growth and maturation of human glomeruli and proximal convolutions from term to adulthood. Pediatrics, 35: 601 (1965).

10. Frohnert, P. P., Hohmann, B., Zwiebel, R., and Baumann, K.: Free flow micropuncture studies of glucose transport in the rat nephron. Pflugers Arch. Ges. Physiol., 315: 66 (1970)

11. Gresham, E. I., Rankin, J. K. G., Makowski, E. L., Meschia, G., and Battaglia, F. C.: An evaluation of fetal renal function in a chronic sheep preparation. J. Clin. Invest., 51: 149 (1972)

12. Imai, M., Seldin, D. W., and Kokko, J. P.: Effect of perfusion rate on the fluxes of water, sodium, chloride and urea across the proximal convoluted tubule. Kidney Intern., 11: 18 (1977)

13. Keyes, J. L., and Swanson, R. E.: Dependence of glucose Tm on GFR and tubular volume in the dog kidney. Amer. J. Physiol., 221: 1 (1971).

14. Kleinman, L. I.: Renal sodium reabsorption during saline loading and dista blockade in newborn dogs. Amer. J. Physiol., 228: 1403 (1975).

15. Merlet-Benichou, C., and deRouffignac, C.: Renal clearance studies in fetal and young guinea pigs: Effect of salt loading. Amer. J. Physiol., I: F178 (1977).

16. Perry, J. S., and Stanier, M. W.: The rate of flow of urine of foetal pigs. J. Physiol., 161: 344 (1962).

17. Robillard, J. E., Kulvinskas, C., Sessions, C., Burmeister, L., and Smith, F. G., Jr.: Maturational changes in the fetal glomerular filtration rate. Amer. J. Obstet. Gynecol., 122: 601 (1975)

18. Robillard, J. E., Sessions, C., Burmeister, L., and Smith, F. G., Jr.: Influence of fetal extracellular volume contraction on renal reabsorption of bicarbonate in fetal lambs. Pediat. Res., 11: 649 (1977).

19. Robillard, J. E., Sessions, C., Kennedy, R. L., Robillard, L. H., and Smith F. G., Jr.: Interrelationship between glomerular filtration rate and renal transport of sodium and chloride during fetal life. Amer. J. Obstet. Gynecol., 128: 727 (1977)

20. Rudolph A. M and Heymann, M. A : Control of the foetal circulation: from Foetal and Neonatal Physiology, Proceedings of the Sir Joseph Barcroft Centenary Symposium, London, 1973, p. 189 (Cambridge University Press, London, 1973).

21. Saloman, Lef glucose 
in blood and urine. Anal. Chem., 31: 453 (1959).

22. Shelley, H. J.: The use of chronically catheterized foetal lambs for the study of fetal metabolism. In: R. S. Combine, R. W. Cross, G. S. Dawes, and P. W. Nathamielsz: Foetal and Neonatal Physiology, p. 360-381 (Cambridge University Press, London, 1973).

23. Tudvad, F.: Sugar reabsorption in premature and fullterm babies. Scand. J. Clin. Invest., 1: 281 (1949).

24. Tudvad, F., and Vesterdal, J.: The maximal tubular transfer of glucose and para-aminohippurate in premature infants. Acta Paediat., 42: 337 (1953). 25. Wen, S. F.: Significance of distal glucose transport in regulating glucose excretion. Clin. Res., 22: 550 (1974) (Abstract)

Copyright (C) 1978 International Pediatric Research Foundation, Inc. $0031-3998 / 78 / 1205-0680 \$ 02.00 / 0$
26. Wen, S. F.: Micropuncture studies of glucose transport in the dog: Mechanism of renal glycosuria. Amer. J. Physiol., 231: 468 (1976).

27. The authors gratefully acknowledge the assistance of Mrs. Marilyn Simpson in the preparation of this manuscript.

28. This research was supported by Research Grant HD 08953 from the National Institute of Child Health and Human Development.

29. Requests for reprints should be addressed to: Jean E. Robillard, M.D., Department of Pediatrics, Division of Nephrology, University of Iowa Hospitals, Iowa City, IA 52242 (USA)

30. Received for publication June 1,1977.

31. Accepted for publication August 16, 1977.

Printed in U.S.A. 